\title{
HOMOPARENTALIDAD Y ACCESO A LA SUBJETIVACIÓN Y SALUD MENTAL DE LOS HIJOS: REFLEXIONES DESDE EL PSICOANÁLISIS
}

\author{
Blanca L. Doménech Delgado \\ Universidad de León \\ blanca.domenech@unileon.es
}

Recibido: 27-01-2010

Aceptado: 12-04-2010

\section{Resumen}

El artículo aborda cuestiones relativas a la homoparentalidad y sus implicaciones para la salud mental de los hijos. Desde el psicoanálisis se relaciona la psicosis con la reducción de la estructura familiar a la vinculación madre-hijo, con la exclusión del padre y con la negación de la diferencia sexual, pero es menester reflexionar qué se entiende por padre, madre o por funciones paterna y materna. Aunque la familia se soporta en elementos biológicos, sin embargo, la biología no explica la familia. Lo que nos constituye realmente como humanos no es la familia sino la "familiarización", la forma en que se traban los primeros vínculos y la forma en que la cultura limita y ordena esas primeras interrelaciones. La salud mental depende de la forma en que se interiorice la ley que pone coto al goce entre el adulto y el niño y ubica a cada miembro en una posición determinada. No es la diferencia anatómica de los padres o la heterosexualidad la que da garantías de salud mental. No es, por tanto, el tipo de elección del objeto de amor de los padres lo que determina la salud mental de los hijos.

Palabras clave: homosexualidad, homoparentalidad, diferencia sexual, función paterna, función materna, nombre del padre, metáfora paterna, subjetividad, salud mental, deseo de hijo, psicoanálisis. 


\begin{abstract}
The article deals with homo-parental related questions and its implications in children's mental health. From psychoanalytic viewpoint, psychosis is connected to the reduction in family structure to a mother-child bond, the exclusion of the father and a denial of sexual difference. However, it is necessary to meditate over what is understood by the concepts "father" or "mother", as well as by paternal or maternal functions. Despite the fact that family is sustained on biological elements, however, biology cannot fully explain it. Family doesn't define us as human beings, but rather "familiarization"- the pattern of the first family bonds and the manner in which culture limits and orders them. Mental health is conditioned by the assimilation of the law that restricts the Jouissance between adult and child and places each member at a concrete position. It is not determined by either anatomical differences between parents or heterosexuality. Therefore, the parents' choice of their object of love does not influence their children's mental health.
\end{abstract}

Key words: homosexuality, homoparental relationships, sexual difference, paternal function, maternal function, name of the father, paternal metaphor, subjectivity, mental health, desire of a baby, psychoanalysis.

\title{
1. Introducción
}

La homoparentalidad, íntimamente asociada a la homosexualidad, es a la vez una exigencia de reconocimiento, un cuestionamiento al orden establecido y una propuesta de replanteamiento de algunos esquemas teóricos disciplinarios.

Que es una exigencia de reconocimiento es algo que alude al derecho. Los hombres y mujeres homosexuales reivindicaban, aunque fuera desde la anormalidad, su derecho a la singularidad de su destino e impugnaban la familia por considerarla símbolo de la opresión en materia de prácticas sexuales. Desde hace poco más de treinta 
años en la sociedad occidental sujetos calificados de invertidos, perversos o enfermos mentales, que reivindicaban la diferencia, aspiran ahora a conseguir, en tanto que ciudadanos, el derecho a constituir una familia y el derecho a la filiación. Aparece un deseo de normalizar su diferencia que ha provocado el rechazo y el temor a que esta pretensión sea signo de la decadencia de los valores tradicionales de la familia, del padre y de la autoridad en todas sus manifestaciones. Como señala Roudisnesco (2004) lo que perturba no es la impugnación del modelo familiar sino la voluntad de los homosexuales de someterse a dicho orden familiar. Dicha reivindicación parece amenazar los pilares de la sociedad, en la medida en que la familia es la institución de la que se vale la sociedad para asegurar la continuidad y crianza de sus miembros, así como conformar el psiquismo de los recién nacidos.

La familia patriarcal, fundada en la soberanía divina del padre, se vio transformada primero por el auge de la biología, al otorgar un lugar central a la maternidad (a la concepción, gestación, parto, lactancia, crianza de los hijos, etc.) ${ }^{1}$ y posteriormente por las reivindicaciones de las mujeres y la irrupción de las nuevas tecnologías reproductivas. Con todo ello, aparece el temor a la abolición de la diferencia, el terror al fin del poder del padre, al poderío ilimitado de lo materno identificado de diversas formas a lo femenino y a la mujer- y visto siempre como sospechoso o amenazante (Iriarte, 1996; Loraux, 1996 y Tubert, 1996a). Sin orden paterno pareciera que la familia supusiera una perversión de lo que constituye la célula básica de la sociedad, quedara sometida a un hedonismo fuera de toda ética.

\footnotetext{
1 Tradicionalmente la contribución fisiológica a la procreación se ha codificado de manera diferente para hombres y para mujeres (Chodorow, 1978 y Tubert, 1996 y 1997). La relación con el hijo, por tanto, se ha imaginado también de forma desigual. La maternidad se ha construido como nutrir y dar a luz, mientras que la paternidad ha sido significada como el acto de engendrar, ser creativo y como la transmisión del nombre. Dicha creatividad está asociada a la divinidad, a la potencia y a la autoridad. Dios crea al primer hombre y le otorga el poder de continuar la creación por medio de su simiente, sin referencia al principio femenino. El Génesis es el registro minucioso de una sucesión genealógica masculina. El descubrimiento del óvulo, su naturaleza y función en el siglo XIX, el auge de lo genético y los descubrimientos de Mendel sobre la contribución hereditaria de ambos progenitores, va a cobrar valor a partir de mediado el siglo XX.
} 
Que la homoparentalidad suponga también un cuestionamiento al orden establecido viene determinado por las creencias que sostienen posiciones conservadoras respecto a la sexualidad y la familia. Consideraciones que influyen en la concepción de la homoparentalidad y la salud mental de los hijos. Dichas creencias podríamos resumirlas, siguiendo a Maffia (2007), en los siguientes puntos:

$1^{\circ}$ ) Que los sexos son dos masculino y femenino, de modo que la dicotomía anatómica conlleva a una dicotomía genérica necesaria para la constitución de la identidad sexual.

$2^{\circ}$ ) Que el sexo es sólo para la reproducción. Lo cual implica que cualquier práctica sexual, no sólo la homosexual, que no estuviera aplicada a la reproducción, es una practica no aceptada. La sexualidad queda, así, reducida a la penetración de un pene en una vagina sin protección y con las posibilidades de procreación.

$3^{\circ}$ ) Que el sexo, la sexualidad, el amor y el deseo de un hijo son cuestiones exclusivamente relacionadas con la naturaleza o con las hormonas, el instinto y/o se basan únicamente en la biología, fisiología, genética. Toda otra consideración indicaría un fallo o una degeneración de la naturaleza o de la moral.

$4^{\circ}$ ) Que la familia es una unidad natural, con una lógica ajena a la política y a la cultura. Desde posiciones conservadoras no se considera a la familia como un conjunto de sujetos, cada uno con sus intereses, que pueden estar en conflicto. Y, en todo caso, ese conflicto de producirse hay que saldarlo de acuerdo con unas relaciones naturales y jerarquizadas: el varón sobre la mujer, el marido sobre la esposa, le padre sobre la madre, la autoridad de los padres sobre los hijos y la de los hijos varones sobre las hijas mujeres. La familia, entendida como unidad natural, conlleva unas relaciones entre sus miembros que son, por naturaleza, de orden jerárquico.

$5^{\circ}$ ) Que todo niño o niña necesitan de un padre y una madre para la constitución de su psiquismo e identidad sexual. En consecuencia, las parejas homosexuales no pueden brindar a los hijos una imagen diversificada de la diferencia sexual anatómica, necesaria para el desarrollo del psiquismo, de la construcción de su 
identidad sexual o de su salud mental. De modo que el límite a la realización personal y privada de los adultos es el derecho de los niños.

$6^{\circ}$ ) Que existe una transmisión hereditaria o imitativa entre la sexualidad del adulto y el desarrollo psicosexual de los hijos. De modo que los hijos "heredarían" la homosexualidad indeseable de los padres.

$7^{\circ}$ ) Que la homosexualidad, como toda sexualidad no aplicada a la procreación, tiene su encarnación en una pareja homosexual. La homoparentalidad como derecho representa una exhibición pública de esta práctica.

Hemos afirmado que la homoparentalidad constituye, también, una propuesta de replanteamiento teórico y ello, entendemos es así, por varias razones:

a) Porque la posición que se adopte ante la homoparentalidad está relacionada de modo muy estrecho con la perspectiva teórico-clínica que se tenga ante la homosexualidad. Si se considera esta última como perversión, enfermedad o trastorno psíquico es indudable que se afirmará que la homoparentalidad supone un riesgo elevado para los niños criados en este tipo de prácticas por lo que supondría de transmisión desde la propia familia de unas experiencias y valores perjudiciales para su salud mental. Pues bien, la homosexualidad como pecado nefando, degeneración moral y sexual, como perversión, patología o trastorno físico o psíquico, necesitado de tratamiento tiene una larguísima tradición. La Asociación Psiquiátrica Americana (American Psychiatric Association, APA), con un amplio ámbito de incidencia en la psiquiatría occidental, incluyó durante años la homosexualidad en su listado de trastornos mentales. Posteriormente limitó el diagnóstico a la homosexualidad egodistónica. No fue hasta 1973 que esta categoría fue eliminada del Manual Diagnóstico y Estadístico de los Trastornos Mentales.

b) Porque la propuesta de nuevos modelos familiares, exige una reflexión acerca de las razones que llevan a hombres y mujeres a constituir una familia y/o a desear tener un hijo. Requiere cuestionar la naturalidad del deseo sexual, 
la sexualidad dirigida exclusivamente a la reproducción, o un replanteamiento acerca de lo instintivo de la procreación. Obliga, también, a repensar la noción de familia como una unidad natural cuyo fin único es la procreación y el cuidado instintivo de la prole.

c) Porque el tema de la homoparentalidad requiere una reflexión y replanteamiento teórico respecto a la importancia de la estructura familiar y de los padres en la construcción de la subjetividad, la identidad de género y la identidad sexual en el ser humano.

¿Qué puede decir el psicoanálisis frente a estas cuestiones? La unión homosexual no es equivalente a una familia monoparental, ni a una familia en la que falte algún progenitor y convivan juntas personas de un mismo sexo (por ejemplo una mujer heterosexual conviviendo en el hogar con la madre, una hermana o con la suegra, aunque ello suponga la ausencia de un varón en dicho hogar). La unión homosexual es una unión bipersonal de un mismo sexo y alude al deseo sexual mutuo que las une. La duda que se plantea es si desde este nuevo modelo de familia se podrán brindar al niño la imagen diversificada de la diferencia sexual anatómica necesaria para el desarrollo del psiquismo infantil, de su subjetividad, de la construcción de su identidad sexual y de su salud mental. ¿Tiene algo que aportar el psicoanálisis a esto?

En la teoría psicoanalítica, asuntos como la admisión de la diferencia anatómica, las funciones materna y paterna, la concepción del complejo de Edipo -en su versión de un padre, una madre y un hijo-, la prohibición del incesto como ley simbólica representada por el padre, etc., son cuestiones básicas explicativas del deseo humano e íntimamente relacionadas con la salud mental. El tema es de una complejidad que sobrepasa las posibilidades de este artículo. No pretendemos abarcarlo en su totalidad, pero si hacernos algunas preguntas y reflexiones teóricas.

La homoparentalidad obliga a repensar las nociones de paternidad, maternidad y filiación. El psicoanálisis ha cuestionado la naturalidad de estos conceptos, de estas relaciones humanas $\mathrm{y}$ ha sostenido que se trata de construcciones culturales 
polimórficas, extremadamente complejas, y no exclusivamente de orden biológico. La familia no es una unidad natural -inducida por la supuesta naturalidad de la diferencia sexual, la unión de un hombre y una mujer-, sino que interviene otro orden de realidad que no compete exclusivamente al orden biológico. No obstante, dentro del propio psicoanálisis, no existe una única posición. Tampoco la obra freudiana es un todo unitario y coherente. Como han señalado Laplanche (1987; 1992 y 1993)² y Gutiérrez Terrazas (2002), la revolución copernicana que suponen los descubrimientos freudianos no impide que el propio Freud se extravíe hacia postulados teóricos más conservadores, peleando entre el saber de la época y un campo y objeto de estudio nuevo que se le está desvelando. La obra de este autor, por tanto, admite múltiples lecturas de las que derivan posiciones teóricas diversas. Nuestro objetivo es abrir un espacio para la reflexión acerca de cuestiones básicas para afrontar el tema de la homosexualidad, la homoparentalidad y su relación con la salud mental. ¿Qué es el deseo, cómo se

${ }^{2}$ Laplanche tiene el mérito de haber evidenciado lo que él mismo ha denominado "falsos asentamientos de la teoría psicoanalítica". Su revisión de conceptos tan capitales para el psicoanálisis como los de pulsión, inconsciente, narcisismo o relación de objeto, despojándolos de su carga biológica y de los supuestos endogenistas, permiten re-centrar el objeto del psicoanálisis: lo inconciente, como fundado por el otro. En su obra Nuevos fundamentos para el psicoanálisis (Laplanche, 1987) replantea desde otra óptica el problema de la identidad sexual en la teoría del psicoanálisis. Este autor (Laplanche, 1993) expone las razones de lo que denomina el "extravío biologizante" de Freud e insiste en que lo más revolucionario de la obra freudiana es el descubrimiento la seducción originaria, de la implantación de la sexualidad en el niño por parte de los adultos que cuidan de él, como efecto de la sexualidad inconsciente que subyace a estos cuidados maternales y paternales. Señala, así, cuál es el verdadero origen de la sexualidad y el deseo infantil. Laplanche rescata la primitiva teoría freudiana de la seducción sexual y le otorga otra dimensión, en el sentido que esa primera seducción sería el proceso a través del cual el niño se ve enfrentado con una serie de mensajes de índole sexual, desconocidos para él y para el propio adulto que los emite. Parte de estos mensajes será simbolizada, pero siempre quedará un resto no "metabolizable", indescifrable, que sería lo que constituiría el inconsciente. Esta concepción del origen del psiquismo y de la sexualidad infantil como implantada por el otro supone cuestionar aquellos conceptos que son centrales en la teoría psicoanalítica, ya que no sólo el origen de la sexualidad infantil y del inconsciente proviene del otro, sino también las vías de simbolización que le son propuestas al niño para calmar su angustia y afrontar lo que Freud denomina los "enigmas" de la infancia (es decir, aquellos que atañen al origen de la diferencia entre los sexos, la sexualidad entre los padres, y de la propia concepción y nacimiento). Enigmas que determinan la elaboración infantil de las llamadas "teorías sexuales infantiles". 
constituye, cómo se construye el objeto de amor, el objeto sexual, qué nos hace llegar a desear como sujetos sexuados y de qué depende la salud mental?

\section{La homosexualidad como enfermedad mental}

No vamos a entrar a discutir acerca de qué es la normalidad, los distintos criterios para definirla, o como concretar lo que entendemos por anormalidad. Tan sólo queremos aludir, recordando a Foucault (1975), que es la cultura la que determina qué conductas o tendencias sexuales son consideradas normales o patológicas. Factores sociales, políticos, religiosos, históricos, tecnológicos y las diversas manifestaciones del poder influyen en su teorización y abordaje. La socialización de los propios terapeutas (psiquiatras o psicólogos), el paradigma científico desde el que éstos hablan y su perspectiva teórica -e incluso religiosa- es seguro que afecte sus juicios sobre normalidad o patología.

Para los partidarios del discurso psiquiátrico del siglo XX la homosexualidad ha sido pensada siempre como una anomalía psíquica, mental o de naturaleza constitucional. En cualquier caso, ha sido concebida como la expresión de un trastorno de identidad. No es sino hasta la década de los años setenta, y por influencia de los grandes movimientos de liberación sexual, que la homosexualidad deja de ser considerada como una enfermedad para ser tratada como una práctica sexual. Como hace constar Roudinesco (2004: 202) la Asociación Americana de Psiquiatría (APA), decidió tras un referéndum retirar la homosexualidad de su lista de desordenes mentales. Incapaz de definir y ponerse de acuerdo acerca de la naturaleza de la homosexualidad, la APA organizó una votación entre la comunidad psiquiatrita sobre la inclusión o no de la homosexualidad en su listado. En 1973 se retiró la homosexualidad del Manual Diagnóstico y Estadístico de los Trastornos Mentales (DSM). Trece años después, en 
1987, sin debate teórico alguno, la APA elimina la palabra perversión para sustituirla por el término de "parafilia",

En 1975, la Asociación Norteamericana de Psicología adopta la misma posición que los psiquiatras. Esta misma Asociación en 1994 establece que la homosexualidad es una forma de expresión de amor y sexualidad de una minoría. El intento de un psicoterapeuta de cambiar la orientación sexual de un paciente o de remitir un paciente a una institución que se ocupe de estas prácticas es considerado fuera de los principios éticos que se exige a los miembros de la asociación.

Roudinesco (2004) indica, también, cómo desde esta última Asociación se recomendó a los profesionales de la salud mental renunciar a sus prejuicios homofóbicos y realizar investigaciones de campo con familias homoparentales. Gays y lesbianas quisieron probar que eran buenos padres y que sus hijos -adoptados, procedentes de otras familias recompuestas, o procreados artificialmente- se comportaban tan bien como aquellos otros criados en familias heterosexuales. Se perseguía someter a prueba las aptitudes psicológicas de los homosexuales para ser padres y determinar, luego, si sus hijos corrían más riesgos que los demás de sufrir depresiones, trastornos psicóticos, adoptar comportamientos asociales, ser víctimas de abusos sexuales por parte de otros adultos, transformarse en abusadores pedófilos, si eran capaces de orientarse en el señalamiento de las diferencias anatómicas o si eran más susceptibles de convertirse más tarde en homosexuales. Se perseguía probar si las parejas homosexuales serían padres con potencialidad para producir efectos patógenos. Entre los años 1973 y 1995 se llevaron a cabo decenas de investigaciones de este tipo que no aportaron demasiada luz, pero aliviaron las angustias de los padres

\footnotetext{
${ }^{3}$ No obstante, hoy alrededor de 80 países en el mundo criminalizan la homosexualidad y condenan los actos sexuales entre personas del mismo sexo con penas de prisión e incluso pena de muerte.
} 
homosexuales al no poderse mostrar que existiera una problemática mayor que en los hijos de familias heterosexuales (Roudinesco, 2004 y Denis, 2007) ${ }^{4}$.

Ahora bien, reducir la homosexualidad a un comportamiento sexual y separarla del funcionamiento psíquico y de sus emociones resulta empobrecedor y limitante respecto a la consideración de la subjetividad. El aporte fundamental de Freud, es el estudio del deseo humano, el haber demostrado que todo el psiquismo se construye en base al desarrollo de la organización de la sexualidad, esto es, que no podemos describir el psiquismo por un lado y la sexualidad por otro, sino constatar la intrincación de ambos aspectos, la existencia de una psicosexualidad. No obstante la cuestión que queda por discutir es qué efectos tiene sobre esa psicosexualidad del nuevo ser la homosexualidad y la identidad de sus progenitores.

\footnotetext{
${ }^{4}$ Como señalan estos autores la investigación sobre homoparentalidad es de una gran complejidad y controversia. En las situaciones de niños adoptados o nacidos a partir de múltiples técnicas reproductivas, nos encontramos ante una irreducible pluralidad de origen, que exigiría una enorme matización de las investigaciones. Muchas de de las investigaciones presentan fallos metodológicos importantes. En algunos casos, porque sólo se ha investigado sobre los hijos de padres militantes de asociaciones de Gays o Lesbianas, comprometidos en la lucha por el reconocimiento de un derecho. En otros, porque la muestra elegida corresponde a hijos procedentes de parejas heterosexuales que se han divorciado y han constituido posteriormente parejas lésbicas o gays que comparten la crianza de esos hijos. En otros, porque las pruebas a las que fueron sometidos los niños se basan en escalas de comportamiento completadas por los mismos padres. También, porque no se ha tenido en cuenta la presencia o no de una patología previa, ni las razones que llevan a adoptar o a apelar a técnicas de fertilización artificial, o porque se han evaluado los efectos a corto plazo, sin seguimiento longitudinal; porque se centraron en elementos de comportamiento y emotividad muy someros, o en tramos de edad muy bajos, por la dificultad en determinar si las manifestaciones conductuales de los niños criados así derivan de un entorno que sigue juzgando la homosexualidad como amenazante, peligrosa o anormal, o por los propios comportamientos de los padres derivados de sus temores relativos al futuro de los hijos en situaciones de excepcionalidad, etc. No obstante, lo que se ha perseguido no es averiguar de qué índole serían los efectos futuros en los niños y en la sociedad general, sino que -bajo el mito de la existencia de un entorno familiar feliz y saludable atribuible a las familias heterosexuales-, se persiguió descubrir los posibles efectos negativos de la homoparentalidad como si esta fuera un "bloque uniforme".
} 


\title{
3. Posición del psicoanálisis respecto a la homosexualidad
}

\author{
El psicoanálisis no tiene una posición unificada respecto a la
} homoparentalidad, ya que coexisten en su interior diferentes teorías, las cuales otorgan diverso peso a la diferencia sexual anatómica, adoptan posiciones diferentes respecto al complejo de Edipo y a la construcción de la identidad sexual.

Puede afirmarse que Freud rompió con el discurso psiquiátrico del siglo XIX que concibe la homosexualidad como una tara, una degeneración maldita y depravada. En su obra de 1905 "Tres ensayos de teoría sexual” Freud habla de inversión, pero en 1910 en su texto "Un recuerdo infantil de Leonardo da Vinci" renuncia a ese término y habla de homosexualidad ${ }^{5}$. Freud (1935) sostiene que la homosexualidad puede no ser una ventaja, pero ni constituye un vicio, ni puede ser considerada como enfermedad,

\footnotetext{
${ }^{5}$ La cuestión de la homosexualidad es tratada en numerosas obras. Sin ánimo de ser exhaustivo citamos algunas obras en dónde Freud aborda el tema. En "Tres ensayos para una teoría sexual" (1905) sostiene que el objeto es un reflejo de la naturaleza bisexual. Cuestión que, con relación a la identificación, vuelve a tratar en "El Yo y el Ello" (1923) y en la "31 ${ }^{a}$ Conferencia: La descomposición de la personalidad psíquica" (1933). En "El tabú de la virginidad" (1917-18) describe una fase temprana, masculina en la mujer que entiende tiene más que ver con el narcisismo originario que con el amor de objeto. En 1920 "Sobre la psicogénesis de un caso de homosexualidad femenina" y en relación con la joven homosexual pone el foco en el rol del complejo de Edipo y dice que la niña, primero desea tener un bebé como su madre y luego pasa a tener una fuerte fijación con su padre de quien espera recibir un hijo. Habla de cómo al sentirse traicionada por el padre en esta pretensión se aleja de él y de su feminidad; se identifica con la figura masculina y elige como objeto de amor a otra mujer. En Introducción al Narcisismo (1914: 87), Freud explica la elección de objeto narcisista bajo las tradicionales fórmulas: Se ama "lo que uno mismo es" (es decir, a sí mismo), a "lo que uno fue", a "lo que querría ser" y a "la persona que fue parte de sí-mismo propio". Es decir, la elección de un objeto parecido a la propia persona, mejor dicho, a la imagen o al ideal de uno mismo. Se elige a alguien bajo este modelo, aunque no exista una correspondencia total. Sin embargo, no significa necesariamente, una elección homosexual o la elección de alguien idéntico. El motor de esta elección se encuentra siempre en alguna identidad oculta. Amar lo que se querría ser supone que se puede elegir el objeto de amor bajo el modelo de la propia persona. Da así importancia al mecanismo de la identificación. Así, por ejemplo, el hombre podría buscar otro hombre joven, como lo fue él, para amarlo como la madre le amó. En "El yo y el ello" (1923) expone lo complejo que es el tema de la investidura de objeto y de la identificación y cómo no se diferencian al principio. En "El fetichismo" (1927) aborda la cuestión de la desmentida en relación con el descubrimiento de la diferencia sexual anatómica, lo que llevaría unida una "escisión del Yo". Se pregunta por las razones que pueden llevar a una persona de sexo masculino a volverse homosexual a consecuencia de la percepción de la diferencia anatómica y el temor a la castración, y se cuestiona si es una experiencia por la que todo niño pasa. En sus obras póstuma "Esquema del psicoanálisis" (1938) y "La escisión del yo en el proceso defensivo" (1940) profundiza en cómo puede articularse esa desmentida con la idea de escisión del Yo. De otro lado, hay que decir que Freud siempre sostuvo la naturaleza bisexual, y que bajo una heterosexualidad manifiesta puede subyacer una homosexualidad latente.
} 
sino una variación de la función sexual. Y ejemplifica que son muchos los grandes hombres que han sido homosexuales (Platón, Miguel Angel, Leonardo da Vinci, etc.). Perseguir la homosexualidad como un crimen constituye una gran injusticia. Por otro lado asevera, también, que es vano intentar transformar a un homosexual en heterosexual. La elección de objeto no viene determinada genéticamente, es una cuestión que se realiza en los primeros años de la vida y depende de las peculiares vivencias y acontecimientos que cada ser humano ha experimentado. Sin embargo, las contradicciones inherentes a la teoría, la enorme complejidad del tema y la ingente diversidad y problemática clínica, dan pié a dificultades para llegar a conclusiones claras al respecto. En 1921 Freud escribe una carta a Ernest Jones en la cual dice que la homosexualidad en sí misma no es suficiente razón para excluir a un candidato de la formación psicoanalítica, mostrando así que no considera que sea una patología.

No obstante, y como recoge Roudinesco (2004) muchos de los discípulos y herederos de Freud mostraron una extrema intolerancia hacia la homosexualidad. La cuestión dividió a los miembros de la comunidad psicoanalítica a partir de 1921. Sostenidos por Karl Abraham, los berlineses se opusieron a otorgar a los homosexuales el derecho a ser psicoanalistas ${ }^{6}$. Respaldado por Freud, Otto Rank se opuso a esta directiva. Desde esta última posición se recordó que existían diferentes tipos de homosexualidad y que cada caso particular merecía un examen específico. Contra esto Ernest Jones se posiciona del lado de los berlineses y proclamó que la homosexualidad era "un crimen repugnante" que atraería grave descrédito si algún psicoanalista lo

\footnotetext{
${ }^{6}$ Aunque la cuestión se plantea sobre si pueden o no los homosexuales ejercer el psicoanálisis, lo que subyace a esta polémica es la idea de la salud mental de los homosexuales.
} 
cometiera $^{7}$. Ahora bien, la prohibición a los homosexuales de acceder a la profesión psicoanalítica se prorrogó sin llegar a ser nunca una regla escrita en los estatutos de la Sociedad Psicoanalítica Internacional, de forma que tampoco exigía derogarla. Las posturas de psicoanalistas posteriores han sido diversas, desde los que se posicionaron del lado de la consideración de un trastorno de personalidad de diferente naturaleza, los que sostenían la necesidad de intervenir para encauzar la homosexualidad hacia la heterosexualidad, hasta aquellos que no la consideraron una patología, sino un modo de elección de objeto de amor.

Con todo, podemos sintetizar la posición del fundador del psicoanálisis respecto a la homosexualidad bajo una serie de argumentos:

1) La identidad sexual no viene dada, no es punto de partida sino un lugar de llegada. Lo que supone que la dicotomía anatómica no conlleva obligadamente una dicotomía en la identidad sexual; esto es, no es correlativa ni a la identidad ni a la elección de objeto sexual.

\footnotetext{
${ }^{7}$ Es preciso recordar que es lo que está sucediendo en Alemania en estos años, y cómo va a influir en el propio movimiento psicoanalítico. Cabe pensar que el rechazo a los homosexuales y a los judíos no es indiferente a la necesidad de adaptarse y convivir con el nazismo, lo que produjo la exclusión y depuración de muchos psicoanalistas por ser judíos, ser de izquierdas, marxistas, etc. y, en consecuencia, también el rechazo a los homosexuales a ejercer la profesión. Pero no son sólo los acontecimientos políticos, sino las propias luchas políticas por el poder y el control de la IPA entre las diversas sociedades e institutos psicoanalíticos para mantener la "pureza teórica" o por constituirse en los auténticos herederos de Freud, frente a la perspectiva no muy lejana de su muerte. Bajo la dirección de Jones, elegido presidente de la IPA se llevan a cabo diversos Congresos y se crea, la "Comisión Didáctica Internacional" que tiene como cometido coordinar los métodos y principios de la formación y admisión de cantidades en las distintas sociedades. Jones va a representar una política de conciliación y apaciguamiento dentro de un régimen nacionalsocialista, tras la huida de Europa de numerosos psicoanalistas y del propio Freud. La IPA, bajo la dirección de Jones abandona, paulatinamente, el proyecto de transformación social que constituye el psicoanálisis y que le había guiado durante décadas; se aleja de los aportes de la filosofía, antropología, sociología y promueve una nueva definición del psicoanálisis, "neutral" política y socialmente, bajo una perspectiva psiquiátrica próxima a la medicina y a lecturas más biologicistas (Montejo, 2009 y Montejo 2009a).
} 
2) La resolución de complejo de Edipo (positivo e invertido) fija un modo de sexualidad. En el caso del homosexual, por diversas experiencias: celos, rivalidad fraternal o edípica, la amenaza de castración o las angustias concomitantes, el sujeto haya su resolución en la forma invertida. Resolución que tiene que ver con la percepción de la diferencia sexual anatómica y la angustia frente a la castración- y que no se produciría hasta el advenimiento de la pubertad.

3) Aunque la identificación primaria, narcisista ${ }^{8}$, es importante en la elección del objeto de amor y en la construcción de la sexualidad, para Freud es la identificación secundaria la responsable de la identificación sexual. En el caso de la homosexualidad se produce una identificación con el progenitor del sexo opuesto y/o una fuerte fijación a la figura materna, eligiendo como objeto de amor a alguien del mismo sexo.

4) La elección de objeto sexual no viene dada de forma natural, sino que depende de una serie de vicisitudes y vivencias. Hay dos modos de elección de objeto de amor que a todo ser humano se le plantea, la narcisista y la objetal. En la homosexualidad lo que se observa es una prioridad en la elección narcisista del objeto de amor.

5) El sujeto deseante no se construye sino en relación con otro que lo constituya. Se precisa la mirada del otro, la erotización del otro. La forma en que ese otro adulto cuidador del niño intervenga con su sexualidad, con su narcisismo, con sus deseos, sus prohibiciones, sus fantasmas, etc., origina el

\footnotetext{
${ }^{8}$ Identificación primaria que es una identificación "ontológica", de pertenencia a la especie humana, que da pié a la imagen del Yo. Dicha imagen se construye por las expectativas de los padres, en virtud de cómo haya sido narcisizado, erotizado por los padres, amado por unos padres con una sexualidad, unos deseos, temores, prohibiciones y fantasmas inconscientes. Los padres atribuyen al hijo intencionalidad como ser humano y es identificándose con esas atribuciones humanas como el bebé se constituye como tal.
} 
Yo del recién nacido y la posibilidad de constituirse en un sujeto deseante. Subjetividad y sexualidad se constituirían simultáneamente.

Ahora bien, en Freud parecen quedar anudadas dos cosas: la elección de objeto sexual e identidad sexual. Lo cual ha llevado a pensar que la identidad de género no estaría definida hasta pasada la pubertad. Sin embargo, y entendemos es lo fundamental, es preciso no olvidar que constituirse en sujeto de deseos exige diferenciarse de ese otro primigenio con el que primariamente nos identificamos y ser reconocido como otro. Exige la existencia de la Ley que prohíbe el incesto. Esto es, requiere, primero, que alguien (tradicionalmente la madre) reconozca al hijo/a como ser en el mundo, como sujeto y no como parte de ella o como objeto de goce propio. Requiere, también, que alguien (tradicionalmente el padre) no esté en una posición de omnipotencia en la que él sea la Ley. Para que se instaure la posibilidad de ser un sujeto deseante ${ }^{9}$, se debe renunciar a ser el goce del otro, el objeto con el que el otro goce, y se debe buscar el goce propio. Un nuevo goce regulado por dicha Ley, por una Ley que regula las relaciones humanas. Una Ley que produce un cambio estructural en el ser humano, que le introduce en un orden diferente al puramente biológico. Renunciar a ser el objeto que satisface a otro, obliga a plantearse el deseo propio y a responsabilizarse del mismo; obliga a buscar una forma propia de gozar, regulada, limitada, admitida por la cultura; un deseo en el que esté presente la diferenciación con el otro materno, pero también el respeto y el derecho del padre. Es decir una Ley que prohíbe los deseos edípicos. En definitiva, una Ley que obliga a admitir un goce limitado, un goce que -en adelanteconlleva culpa si transgrede la ley de prohibición edípica, o que comporta satisfacción si se respeta. Un orden en donde el goce absoluto no es posible, un orden psíquico marcado por la represión cultural. El niño o la niña se identifican con sus progenitores, con los ideales y las prohibiciones culturales representadas en ellos, interiorizan, así, un

\footnotetext{
${ }^{9}$ Es menester precisar que en psicoanálisis cuando se habla de sujeto se está aludiendo al sujeto del inconsciente y que deseo no es sinónimo de deseo voluntario.
} 
orden que no se regula por el mero instinto. Hacen suyo un orden cultural, representacional, simbólico, esto es, un nuevo funcionamiento que permite dialectizar con el otro, compartir el mismo lenguaje. No hay posibilidad de ser sujeto ni de desear fuera de un orden simbólico, salvo en el caso de la psicosis. Este señalamiento del orden simbólico descubierto por Freud es destacado y desarrollado especialmente por Lacan.

\section{La aportación de Lacan respecto a la salud mental y la necesidad del padre}

Debemos a Lacan el énfasis puesto en la estructura psíquica, frente a las manifestaciones conductuales o los síntomas, para comprender la salud mental. La constitución de la estructura para este autor viene determinada por la asunción de la castración y la Ley que prohíbe el incesto, que pone límite al goce, que regula éste dentro de un orden cultural, simbólico. La asunción de la castración ${ }^{10}$, de la imposibilidad de un goce ilimitado, absoluto, es ciertamente normalizante ya que, como acabamos de decir, supone la entrada en un orden que regula los intercambios humanos, especialmente los intercambios sexuales entre padres e hijos, entre generaciones. El problema entre la madre y el hijo/a -en lo referente a la constitución de la estructura psíquica infantil- no se refiere a los cuidados que el bebé reciba o no, sino al goce

\footnotetext{
${ }^{10}$ La castración, tercera modalidad de falta de objeto (las otras dos son la frustración y la privación), es definida por Lacan (1956: 57) como la falta simbólica (no se trata de un problema de anatomías ni se refiere a una castración real) de un objeto imaginario. La castración se refiere también al estado de falta que existe en la madre antes del nacimiento del hijo. Se refiere a un estado de falta. Falta que se percibe en la madre que por ello desea más allá del propio niño/a. Falta en el propio sujeto que se da cuenta que no es el falo imaginario que la madre anhelaba. El niño/a se da cuenta muy tempranamente de que la madre no es un ser completo, autosuficiente en sí mismo, ni que está total y plenamente satisfecha con él, sino que desea algo que está más allá de la relación entre ambos. Así es como el bebé se da cuenta de que la madre desea por fuera de él y entra en la dialéctica del deseo, permitiéndole salir de una posición especular, narcisista para entrar en otra dinámica. Esto es, le permite rotar de la posición de objeto para el otro a la de sujeto deseante. La castración para Lacan denota el momento final del complejo de Edipo en ambos sexos. Ambos deben renunciar a ser el falo para la madre, esto es ser su objeto de deseo (Lacan, 1957: 58). Ambos deben admitir un goce limitado por la Ley que prohíbe el incesto.
} 
prohibido. Es decir, como señala Eric Laurent (1987: 16) "no hay armonía posible entre el niño y la madre ya que entre ambos está el Otro". En función de cómo se asuma o no la Ley que prohíbe el incesto y la castración se van a producir tres estructuras: la neurótica -estructura de la normalidad- en donde se admite la ley que prohíbe el goce. La estructura perversa, en donde se percibe la castración, pero se reniega ${ }^{11}$ de ella. Y, la tercera, la estructura psicótica en donde hay una "forclusión"12 o renegación de la castración. Ahora bien, la homosexualidad no necesariamente pretende pervertir la ley que ordena el goce, la interdicción del incesto, ni siempre conlleva dicha "forclusión". Habría pues que hablar de homosexualidades y no de homosexualidad, y considerar que en los individuos homosexuales existe una pluralidad psicopatológica tan variada como en los heterosexuales. Es decir, que entre los individuos homosexuales pueden darse tantas diferentes estructuras como entre los heterosexuales. Por tanto, no es el objeto de amor elegido lo que determina la salud o la psicopatología, sino la estructura, y ésta viene determinada por la Ley, por la admisión o no de la metáfora paterna y la castración.

Este autor relaciona la psicosis, la locura, con la exclusión del padre en la estructura familiar, con la reducción de la estructura familiar a la vinculación madrehijo (Lacan, 1938) y con la negación de la diferencia sexual. Ahora bien ¿a qué alude la metáfora paterna?, ¿Qué quiere decir la exclusión o la ausencia del padre? ¿Se refiere a la presencia de un varón en el hogar? Empecemos por señalar que el padre no es equivalente al genitor. La pregunta de Lacan, retomada de Freud, acerca de qué es un

\footnotetext{
${ }^{11}$ Mecanismo psíquico por el cual todo niño se protege de la amenaza de la castración. Repudia, desmiente, reniega de la ausencia de pene en la niña, la mujer, la madre y cree por un tiempo en la existencia del falo materno. En la perversión se percibe la falta en la madre y al mismo tiempo se niega a aceptar la realidad de esa percepción traumática. Esto es, es un mecanismo consistente en que el Yo rechaza la idea incompatible con su afecto y se comporta como si la idea nunca se le hubiera hecho presente al yo.

${ }^{12}$ Forclusión es el mecanismo específico de la psicosis. Es el término que utiliza Lacan en su "Respuesta al comentario de Jean Hippolite sobre la Verneinung de Freud" para referirse a la renegación. Para este autor un elemento es rechazado fuera del orden simbólico, exactamente como si nunca hubiera existido (Lacan, 1954: 386-87).
} 
padre es una forma de abordar el problema del significante padre. La distinción lacaniana del padre como real, simbólico e imaginario (Lacan, 1956-57 y 1957-58) pone luz en lo relativo a qué es un padre, cuándo hay un padre, qué influencia tiene en el psiquismo infantil y en la constitución del complejo de Edipo y cuál es su función desde el punto de vista de la estructuración del psiquismo humano.

El padre real es aquella persona -o entidad- que realiza la función paterna. Dicha función es la de limitar, romper la relación incestuosa madre-hijo, trasmitir la prohibición del incesto. Es, por tanto, el centro alrededor del cual gira el Edipo. No se trata de una función social sino de una función estructural. El padre real es aquel que ocupa el deseo de la mujer que no se satisface en el deseo de un hijo. En "El Seminario 7. La ética del psicoanálisis” Lacan (1959-60: 366) explica que es castrador por su presencia y es promovido como "el Gran Jodedor", como aquel que realmente se ocupa del deseo sexual de la madre. Es también aquel de quien se dice que es el padre biológico $^{13}$. Es decir, el padre real no es la función paterna, sino aquél que ostenta su representación. Acceder a la posición de padre y ejercer la función paterna es una búsqueda. Nadie puede alcanzar por entero esa posición, pero sí se parte de la suposición hipotética de que existe alguien que sostiene la posición ideal del padre, sin fallas, alguien que pueda ejercer a la perfección la función. El agente de la castración es el padre real. El fin del complejo de Edipo es correlativo a la instauración de la Ley.

El padre simbólico no es una persona real, sino que se trata de una función, en ese sentido se puede decir que "padre simbólico" es sinónimo de "función paterna", de

\footnotetext{
13 Pero no por ser el genitor -en lo biológico-, sino en la medida en que es en quién la madre tiene puesto su deseo. Si hemos subrayado "de quien se dice" es para señalar que el padre real es aquel que la madre dice que lo es, aquel (¿podemos pensar también en aquella?) que la madre desea, en quien está puesto el deseo materno que concluye también en el deseo de concebir, cuidar y educar un hijo. El padre real es quién - por ser deseado/a por la madre- hace saber, o hace evidente al niño la prohibición incestuosa.
} 
"metáfora paterna" o significante del "nombre-del-padre"14. Dicha función consiste en imponer la Ley y regular el deseo en el complejo de Edipo. El padre simbólico ha de intervenir en la relación dual e imaginaria entre la madre y el niño, introducir una distancia simbólica entre ellos (Lacan, 1956-57). Para determinar la salud mental, no basta con que el niño alcance la heterosexualidad tras el Edipo, sino que el sujeto, niño o niña ha de situarse en una posición sexual de forma que se ubique correctamente con respecto a la función del padre (Lacan, 1956-57 y 1957-58).

El padre simbólico es, también, el mito del padre muerto, del padre de la horda primitiva del que habla Freud en "Tótem y Tabú" (1913) Esto es, el padre simbólico, como he dicho, no es una persona real, está ahí desde antes del origen de la historia, es una función que, precisamente, da lugar a la historia. No es tampoco el legislador, sino el que culturalmente sea el portador de la Ley, el que está investido de este significante. Es el elemento fundamental de la estructura del orden simbólico, lo que distingue el orden de la naturaleza del orden simbólico de la cultura ${ }^{15}$. Es la Ley que prohíbe el incesto, prohíbe el goce con la madre pero permite otras formas de satisfacción, permite las sustituciones. Es, por tanto, el significante de la prohibición. En el complejo de Edipo, este significante ("nombre-del-padre") remplaza a otro significante, al del deseo de la madre, lo que supone la entrada en el mundo normativizado y normalizado. Lacan (1957-58), por ello, habla del complejo de Edipo en tanto "metáfora paterna", porque hay una sustitución del significante del deseo materno hacia el otro, por el de la prohibición, por el significante del "nombre-del-padre". Pero para que alguien esté en

\footnotetext{
${ }^{14}$ Evans (1997, p. 138) señala cómo Lacan juega con la homofonía de <<le nom du père 〉> (el nombre del padre) y <<le"non" du père $>>$ (el "no" del padre), para subrayar la función legislativa y prohibitiva del padre simbólico.

${ }^{15}$ El padre simbólico, el padre muerto, es la forma mítica que cobra una exigencia de anterioridad lógica: la Ley se instaura entre iguales tras su asesinato (Freud, 1913). Esto es, no hay otro origen de La ley que el padre muerto quién, por tanto, queda constituido en el mito como excepción, como el que está más allá de la Ley.
} 
dicha posición metafórica, es obligado que la madre lo convierta ${ }^{16}$ en aquel que con su presencia sanciona la existencia del lugar de la Ley.

El padre simbólico desempeña, pues, un doble papel esencial: el de frustrar al niño de su madre. En palabras de Lacan (1957-58: 177):

"El padre interviene como provisto de un derecho, no como un personaje real. Aunque no esté ahí, aunque llame a la madre por teléfono, por ejemplo, el resultado es el mismo. Aquí es el padre en cuanto simbólico el que interviene en una frustración, acto imaginario que concierne a un objeto bien real, la madre, en tanto que el niño tiene necesidad de ella".

Y, además, desempeña el papel de privar a la madre del objeto de su deseo, del objeto fálico, del hijo. "Es gracias al Nombre-del-Padre como el hombre no permanece atado al servicio sexual de la madre" (Lacan, 1964: 388). Esto es, gracias a la "metáfora paterna" el niño deja estar en posición de objeto, de fetiche e incluso de víctima de la madre.

Ahora bien "El padre está en una posición metafórica si y sólo si la madre lo convierte en aquel que con su presencia sanciona la existencia del lugar de la ley" (Lacan, 1957-58: 202). Esto es, no se trata de que el padre se imponga u obligue privando a la madre del hijo, sino de que se haga presente en la dialéctica deseante de ésta en tanto que mujer. Lo cual, bajo nuestro criterio, puede realizarse de diferentes formas y con diversos medios.

Por último, el padre imaginario es el padre colocado en una posición de igual, de rivalidad, no como padre, sino como hermano en el conflicto edípico. A él se refiere

\footnotetext{
${ }^{16}$ Subrayamos, nuevamente, la idea de que es el deseo de la madre por el otro, por alguien que no es el hijo/a. Es preciso que ella haya interiorizado esa prohibición, también, de utilizar o gozar del hijo. Desde nuestro punto de vista consideramos que lo fundamental no es el sexo del otro que desea la madre, sino la existencia de ese límite, de la prohibición incestuosa interiorizada en su propio inconsciente.
} 
toda la dialéctica de la agresividad, rivalidad, identificación e idealización. Pero también es el padre construido por el niño/a, sin que tenga que coincidir con la persona real del padre. Es más, raramente el niño/a puede captar al padre real debido a la interposición de los fantasmas y del padre simbólico (Lacan, 1956-57). El padre imaginario es además el padre omnipotente, omnisciente, el amo absoluto (Lacan, 1956-57: 276) con el que el niño se identifica y forma su Yo ideal. Pero para llegar a construir su "Ideal del yo" es necesaria una segunda identificación que pasa por la asunción de la metáfora paterna, es decir, la internalización de la Ley que prohíbe el incesto. El "Ideal del yo" pasa a constituir una guía que gobierna la posición del sujeto en el orden simbólico.

En síntesis, entendemos que es preciso diferenciar la función simbólica ejercida por el padre real como representante de la Ley de prohibición del incesto y sus efectos en la estructuración del psiquismo del bebé, de la presencia o ausencia física del padre en la realidad y el entorno material del niño. Lo importante en relación a la presencia del padre en el complejo de Edipo no está en la dimensión de la realidad sino en la simbólica. La trascendencia que Lacan otorga al padre, insistimos, no responde a su existencia como genitor, ni a su presencia física, ni a la imagen que el niño tenga de él, ni a las actitudes más o menos gratificadoras o frustrantes que muestre, sino al lugar que ocupa en el deseo de la madre y a la función simbólica que ha de desempeñar. Es, por tanto, una instancia que está o no en la madre, independientemente del compañero real -si existe- que ella tenga. Que no haya padre tangible no implica que en el niño falle la operación de la metáfora paterna. Lo fundamental tampoco es que el padre real imponga la Ley, sino que esta Ley sea respetada por la madre y por el padre. La intervención del padre es mediada por el discurso de la madre. Es en las palabras de ella y en sus actos donde ha de manifestarse ese respeto a la Ley. Para que esto pueda suceder, la madre la ha de tener incorporada, ha de poder ubicar al bebé en calidad de hijo y al padre como el objeto de su deseo. El padre real es aquel que ocupa el deseo de la madre y -desde ahí- representa la función simbólica. Ubicarse en posición de padre 
real sólo es posible si se tiene incorporado el significante del "nombre-del-padre", al padre simbólico o la función paterna ${ }^{17}$.

\section{Familia homoparental y construcción de la subjetividad}

La familia es un núcleo de relaciones complejo que se transforma incesantemente bajo la presión de múltiples factores, o como la califica Roudinesco (2004), en permanente desorden, dado que no podemos decir que haya existido un único modelo familiar, una única conformación estructural (hombre-mujer e hijos) ni un único modo de entender las relaciones entre sus miembros, de atribuir o definir la paternidad, la maternidad y la filiación (Hurstel, 1997; Knibiehler, 1997; Narotzky, 1997; Tubert 1997 y Tubert 1997a). La familia es un constructo polimórfico variable. Las técnicas de fecundación in vitro o de reproducción asistida han posibilitado enormes cambios (Doménech, 2002 y 2004) y desencadenado tanta confusión social y legal como los cambios en las relaciones de pareja y de familia (matrimonios y emparejamientos sucesivos, hetero u homosexuales, distribución entre diversas personas en el tiempo de las responsabilidades parentales, adopción por parte de personas solteras, homosexuales, etc). ¿De qué forma algunos de estos cambios inciden sobre la salud mental? Entendemos que el psicoanálisis tiene algo que aportar para clarificar este embrollo.

Es cierto que la procreación es biológica, pero la procreación no instituye la familia humana. Es verdad, también, que la familia se soporta en elementos biológicos, pero la biología no explica la familia. Podemos concluir que llevar la misma sangre no hace familia, salvo en el reino animal, porque lo que nos constituye realmente como humanos no es la familia sino la "familiarización", del mismo modo que lo humano no es la sexualidad sino la sexualización, la forma en que se instaura la sexualidad, en que

\footnotetext{
${ }^{17}$ No está sólo en relación con la anatomía del ser que ocupe ese lugar.
} 
el adulto cuidador erotiza las primeras relaciones que establece con el bebé en virtud de su propia sexualidad inconsciente (Freud, 1905 y Laplanche, 1987 y 1992) ${ }^{18}$ y que va a condicionar, determinar o matizar sus ulteriores elecciones de objeto sexual. La familia no es por tanto un dato natural sino un complejo de relaciones, un conjunto de vínculos que se establecen entre sus miembros. Los cambios actuales afectan a la sexualidad y a la procreación. Insistimos en que la naturaleza no crea la familia, lo que históricamente se nos ha evidenciado por esa diversidad familiar. Es decir, no hay nada en la naturaleza que diga qué es ser un padre, cómo ser madre o cómo ser hijo, como tampoco hay nada que nos diga cómo ser hombre o como ser mujer. En el amor, en la relación sexual no existe una armonía pre-establecida, no hay "el hilo y la aguja” que diría Lacan (195657: 51). Si bien es en la familia donde el sujeto traba los primeros vínculos, donde brotan sus primeros sentimientos amorosos, donde construye su identidad, su subjetividad, su identificación como hombre o como mujer, donde se sexualiza, donde, como ha evidenciado el psicoanálisis, el sujeto se encuentra con la Ley que regula su goce e instaura su deseo. Una Ley que supone que un goce ha de ser perdido (aquel que se encontró en esos primeros contactos, besos, afectos, expectativas, anhelos, deseos intrafamiliares) para ser luego recuperado de otra forma, con otras personas fuera de la familia, si bien dejando siempre unas marcas inconscientes que determinan su subjetividad. El primer amor ya es el segundo, “es un reencuentro”, decía Freud (1905: 203), expresando cómo la vinculación con la madre deja unas huellas que constituirán el marco para su futuro amor. Si lo más inmediato para el niño y la niña sería escoger como objetos sexuales a las personas a quienes desde su infancia ama, en virtud de la Ley que prohíbe el incesto renuncia a ese primer goce para "normalizarlo". Humanizar es precisamente eso, hacer entrar el deseo en los límites que la Ley supone. En el caso que nos ocupa, instaurar lo más elemental en el deseo humano, interiorizar la

\footnotetext{
${ }^{18}$ El complejo de Edipo no es algo que se produzca de forma natural o espontánea desde el hijo hacia sus padres, sino que son las expectativas edípicas persistentes en el inconsciente de los padres las que van a generar enigmas y suscitarán también los sentimientos edípicos infantiles. Es decir, podemos pensarlo también yendo del adulto (ya constitutito culturalmente) hacia el niño.
} 
imposibilidad y prohibición de un goce absoluto, sin Ley. Humanizar es interiorizar esa Ley que ordena la forma de gozar, respetando el derecho del otro, admitir el derecho del padre sobre la madre o el de la madre sobre el padre, el derecho del hijo/a a escoger su propio objeto y no ser el objeto propiedad de los padres. Una Ley que pauta los intercambios, pone coto al goce entre el adulto y al niño, y ubica a cada miembro en una posición determinada. La barrera del incesto se erige como una adquisición e imperativo cultural (Freud, 1905). Se necesita, pues, como afirma Naranjo (2006), “desfamiliarizar”, abrir el deseo más allá de la madre, en primer lugar, y de la familia después. Para Lacan en eso consiste el "nombre-del-padre", la "metáfora paterna", la "función paterna”. Ahora bien ¿cómo se piensa la denominada Ley del padre en relación con la familia homosexual?

La antropología estructural sostiene que la prohibición del incesto es la condición de pasaje a la exogamia, lo que implica una formalización y sujeción a la Ley simbólica (que habitualmente es presentada como equivalente a la Ley paterna) e implica también el reconocimiento de la diferencia anatómica de los sexos como la otra condición de un orden social constituido. El psicoanálisis descubrió la forma en que -en nuestra cultura- niños y niñas escenifican o dramatizan en su inconsciente esos deseos prohibidos, la Ley y el castigo que lleva aparejada la trasgresión. También, en un orden patriarcal, se considera que la madre está ligada al hijo de forma primordial y eso supone un goce que impediría una salida simbólica exogámica en la trama de lazos sociales. De ahí que sólo un corte -simbólico- a través de la función paterna permitiría esa salida. Además de la pregunta por la función paterna, cabe hacerse esta otra ¿Cómo se pensaría la función materna en una familia homosexual?

Tradicionalmente el padre (Tubert, 1997) ha representado esa función relacionada con la Ley, con la introducción en un orden simbólico y la madre (Chodorow, 1978 y Bleichmar, 1984 y 1993) ha ocupado esa función de dar vida, atender sus cuidados, libidinizar o narcisizar, introducir la pulsión, crear el deseo de vivir al niño, dar nombre a las necesidades y demandas infantiles, atribuirle sentimientos y demandas humanas, establecer una estrecha vinculación en la que la 
madre supone saber lo que el niño necesita. Es decir, posibilitar esa primera identificación narcisista. Pero es menester que exista un límite a esa vinculación madrehijo/a o padre-hija/o, una prohibición de apropiarse del cuerpo del niño como lugar de goce del adulto, una interdicción de cosificar al hijo y despojarlo de subjetividad. Es necesaria la admisión de un orden que regule esas primeras vinculaciones, un orden que concierne a todos y está por encima del padre y de la madre, un orden que posibilite unas identificaciones secundarias e introduzca al niño en unas relaciones terciadas, simbólicas, mediatizadas, que introduzca la cultura en la subjetividad.

Ahora bien como ha señalado Laplanche (1987 y 1992) y recoge también Bleichmar (1984; 1993 y 2006) lo que determina la producción de la subjetividad es la asimetría adulto-niño y la Ley que limita ese goce primigenio. Ley que, también, podemos denominar "función de corte", función ejercida por quien ocupe el lugar de tercero, del que interviene desde el inicio como separador del vínculo fusional con la madre.

Por tanto no es un determinado modelo familiar, ni qué persona concreta ejerza u ocupa ese lugar, o cuál sea el sexo de la persona que desempeñe dichas funciones. Ejercer la función materna y/o la función paterna no obliga a que sea desempeñada por una madre y por un padre, o por una mujer y un hombre. Podemos, así, cuestionarnos ¿deben estas funciones estar ligadas al género de los padres? O, como se interroga Glocer (2007), esas funciones ¿tienen que estar ligadas a un cuerpo que sostenga un género acorde al mismo? o por el contrario ¿se trata de funciones que cualquiera de los miembros de una pareja homosexual estaría en condiciones de ejercer? Como ya dijimos, hablar de homosexualidades es crear un todo homogéneo donde no lo hay. Tras la aparente homogeneidad de la homosexualidad subyace una enorme diversidad: desde actos homosexuales ocasionales, pasando por homosexualidades de estructura neurótica o normal, pasando por homosexualidades con estructuras clínicas perversas o psicóticas. El ejercicio de la parentalidad de esos homosexuales -igual que sucede con los heterosexuales- exigiría un análisis de dicha estructura, de cómo han incorporado la función de límite, -función paterna-, función de corte, y cómo serán capaces de 
trasmitirla. Si admitimos, pues, que ser padre o ser madre son funciones, no importaría tanto si dicha posición o función es ejercida por hombres o por mujeres sino por cómo se ejerce.

La otra pregunta que queda pendiente es ¿qué pasaría con la admisión de la diferencia sexual tan necesaria para la construcción del deseo? ¿Se puede generar en el hijo dificultades para la simbolización de los binarismos clásicos "madre-padre", “hombre-mujer”?. ¿Cabe pensar que la diferencia sexual podría ser interiorizada, como operación simbólica ${ }^{19}$, desde los códigos de la cultura y como transmisión transgeneracional "atravesando" el inconsciente parental? Freud (1933 y 1933a) ya había señalado la influencia no sólo de los padres, sino también la de aquellas otras personas que han pasado a ocupar el lugar de los padres, educadores, maestros, personas influyentes y arquetipos ideales. Así, refiriéndose al influjo personal de los padres, dirá Freud:

\begin{abstract}
"No sólo es eficiente la índole personal de estos, sino también el influjo, por ellos propagado, de la tradición de la familia, la raza y el pueblo, así como los requerimientos del medio social respectivo, que ellos subrogan. De igual modo, en el curso del desarrollo individual el superyo recoge aportes posteriores continuadores y personas sustitutivas de los progenitores, como pedagogos, arquetipos públicos, ideales venerados en la sociedad" (1938: 145).
\end{abstract}

Es decir, no es sólo la experiencia individual, familiar, sino que los procesos identificatorios y deseantes de los hijos se apoyan en factores intersubjetivos, grupales,

\footnotetext{
${ }^{19}$ Es preciso distinguir la diferencia sexual anatómica de la diferencia simbólica en cuanto lo que representa de incompletud para ambos sexos, en cuanto a que todos -hombres y mujeres- están en falta, en terminología psicoanalítica "castrados". Que el sujeto admita la castración supone la admisión de que no es un ser absoluto, hermafrodita, u hombre y mujer simultánea o alternativamente. Significa poder establecer una identificación como hombre o como mujer, sea esta identificación coincidente o no con su anatomía.
} 
sociales. Si bien, es posible, como apunta Glocer (2007) que las identificaciones provenientes de la cultura pueden entrar en conflicto con aquellas que derivan de la experiencia de uniformidad de géneros en sus padres, pero no implica necesariamente que esto suponga una alteración de su salud mental.

Por otro lado, es preciso tener en cuenta que los seres humanos elaboran su propia "novela familiar", esto es, teorizan acerca de cuál es la razón de su nacimiento y la contingencia que les puso en este mundo, independientemente de quienes sean sus padres. Son preguntas por el enigma acerca del deseo de sus padres. De modo que respecto a estos enigmas infantiles y las preguntas sobre el deseo del otro, sobre el deseo de su madre, o del otro significativo (sea cual fuere su anatomía), respecto a los interrogantes acerca de qué desea ella (o quien ejerza de madre), qué le falta al otro, qué tengo yo para ofrecerle, qué quiere de mí, qué busca en ese otro (pareja de la madre), qué encuentra en ese otro que no lo encuentra en mí, son enigmas infantiles que aluden a la castración, a la falta. Además, como señalan Laplanche (1980 y 1987) y Bleichmar (2007) aunque dicha falta haya sido simbolizada imaginariamente como castración, como ausencia de pene $^{20}$, no remite sólo a anatomías, sino a la existencia del inconsciente del adulto que le cuida, a ese enigma que para el niño constituye el deseo del adulto y que para el propio adulto supone su inconsciente. Un adulto que no sabe de ese inconsciente que subyace en los cuidados que le otorga al niño. La castración alude a la imposibilidad de un ajuste perfecto ${ }^{21}$ entre los deseos del niño y los del adulto, a la imperfección humana de esa vinculación. La castración se refiere a la incompletud radical del ser humano, a lo imperfecto de la comunicación. Lo fundamental de la teoría

\footnotetext{
${ }^{20}$ La ausencia de algo no puede ser percibida, y si la diferencia anatómica es percibida por niños y niñas como que "falta", como "algo han cortado" o "algo de lo que se carece", si así se percibe, es porque existe previamente una concepción teórica acerca de que algo que supuestamente debiera estar ahí, falta. Hay ya una simbolización de la experiencia de pérdida, que se articula con la anatomía y da pié a dicha interpretación cultural infantil.

${ }^{21}$ Es una vinculación imperfecta, en cuanto que no regida por un saber instintivo, no ajustada a un puro saber biológico o genético. Es precisamente lo humano lo que altera este saber o ajuste natural al estar impregnado por el orden cultural, por las prohibiciones, temores, ideas, valores, etc.
} 
de la castración no radica en su anclaje anatómico, aunque así haya podido ser acuñado por el niño en un tiempo y momento histórico y en una cultura patriarcal. Lo que la teoría de la castración señala es esa falta constitutiva. Por tanto, sean los padres del mismo sexo o de diferente sexo, lo importante es la forma en que esa falta estructural es captada y la forma en que se piense el deseo parental, se novele su propia historia.

\section{El deseo de un hijo}

Desear constituir una familia no tiene, necesariamente, raíces sexuales. Se puede desear fundar una familia por otras consideraciones como son la necesidad de amor, de, protección, de autoafirmación, de apego, de trasmitir un patrimonio, etc. Sin embargo, en el deseo de un hijo, si está presente la sexualidad. Las nuevas tecnologías reproductivas han posibilitado el poder ser madre sin pasar por la relación sexual, pero no sin tomar en consideración la sexualidad, la castración y la admisión de la diferencia (Tubert, 1991 y Doménech, 2002 y 2004). Las razones conscientes que llevan a hombres y a mujeres a desear un hijo varían, pero en las razones inconscientes intervienen cuestiones como son las primeras identificaciones narcisistas con la madre por parte tanto de los niños como de las niñas, participa, también, el conflicto edípico en sus distintas variantes (bien sea deseando un hijo como sustituto simbólico de una carencia primordial o bien deseando reemplazar a uno de los progenitores), y, depende de la posición que se adopte como sujeto respecto a la identificación sexual. Es preciso señalar que en el deseo de un hijo intervienen también otros factores -relacionados con los recientemente mencionados- como son el deseo de trascendencia ${ }^{22}$ y supervivencia

\footnotetext{
${ }^{22}$ Frente a la angustia de la propia desaparición, de la muerte, de los límites humanos, hombres y mujeres pueden desarrollar un sentimiento de perpetuación o de continuidad a través de sus hijos. Ahora bien, la cuestión es investigar que subyace a ese deseo de trascender más allá de la propia vida, de analizar si ese anhelo de trascendencia oculta una negación de la muerte, de la castración y un no reconocimiento del hijo como sujeto para percibirlo y tratarlo como un objeto propio, para su goce.
} 
física en la memoria del hijo, el deseo de vivir a través de los hijos a modo de una segunda oportunidad, el anhelo de satisfacer a la propia madre, reparar un daño, negar un duelo o la pérdida de otro hijo, así como otros motivos como el de acompañamiento en la vejez, de prestigio social, de asegurar la herencia, etc. Es decir, el deseo de un hijo, se independiza de la elección de objeto homo o heterosexual. Pero si lo que perseguimos es tomar en cuenta la salud mental de los hombres y mujeres, padres y madres, o analizar la posibilidad o no de producir una estructura perversa y/o psicótica, el deseo de un hijo, aunque conlleva un afán por conseguir ese goce imposible, por negar toda limitación y muerte y por recuperar el narcisismo primigenio, exige, además, el reconocimiento de la castración, la admisión de la diferencia sexual y la instauración del Ideal del yo (Doménech, 2008). La cuestión se plantea, entonces, en los mismos términos en que hemos estado reflexionando. No podemos hablar de si es o no perjudicial para los hijos el disponer de una familia homoparental. No es la elección del objeto de amor y del objeto sexual, por sí misma, la razón que asegura la salud mental. Respecto al ejercicio de la homoparentalidad, este puede ser tan heterogéneo como el de la heteroparentalidad. El deseo de un hijo de hombres o mujeres homosexuales ha de ser estudiado en sus características individuales, caso por caso.

\section{Conclusiones}

El psicoanálisis ha ayudado a separar la anatomía de la asunción de un género, el destino biológico de la asunción de capacidades o de propiedades. La paternidad, la maternidad y las parentalidades dependen más de inscripciones psíquicas que de realidades corporales. Las funciones paternas y maternas -pensadas desde el psicoanálisis- podrían ser ejercidas por seres hablantes varones o mujeres indistintamente. La diferencia anatómica de los padres no da garantías de salud, como ya sabemos. Entendemos que tampoco hay razones para suponer que la homoparentalidad pueda generar psicopatologías graves. Lo esencial estaría 
determinado por el lugar en el que se posicionen, la transmisión a la que dieran lugar, la forma en que se libidinizara al hijo. En el fantasma edípico de la escena primaria no importaría tanto el sexo de cada uno de los integrantes de la pareja imaginaria, sino la estructura de exclusión que lo constituye, la asunción de la función de corte, función paterna, sea quien fuere quien la ejerza. El trabajo psíquico adulto necesario para conducir al recién nacido a la vida psíquica, creemos, no dependería tanto del sexo de la pareja conyugal sino de la salud psíquica y de la intención de amor de la pareja. 


\section{BIBLIOGRAFÍA}

- Bleichmar, S. (1984): En los orígenes del sujeto psíquico. Del mito a la historia. (1 Edición 1986; 2a reimpresión 1999). Buenos Aires: Amorrortu.

. (1993): La fundación de lo inconsciente. Destinos de pulsión, destinos del

sujeto. ( $1^{\text {a }}$ Edición, 1993; $1^{\text {a }}$ reimpresión, 1998). Buenos Aires: Amorrortu. . (2006): Paradojas de la sexualidad masculina. Barcelona: Paidós.

- Chodorow, N. (1978): El ejercicio de la maternidad. Psicoanálisis y Sociología de la Maternidad y Paternidad en la crianza de los hijos. Barcelona: Gedisa.

- Denis, P. (2007): "De la dificultad de estudiar la homoparentalidad". En Rotenberg, E. y Agrest Wainer, B. (comp.): Homoparentalidades. Nuevas familias. Buenos Aires: Lugar Editorial, pp. 131-137.

- Doménech Delgado, B. (2002): "Maternidad y nuevas tecnologías reproductivas". En A. I. Blanco G.; B. Doménech Delgado; M. S. López Rodríguez y R. Marcos Santiago (coord.): Nuevas visiones de la maternidad. León: Secretariado de Publicaciones y Medios Audiovisuales de la Universidad de León, pp. 97-122.

. (2004): "Maternidad y salud mental". En Reflexiones teóricas y políticas desde los feminismos". Ponencia al III Congreso Internacional de AUDEM (Asociación Universitaria de Estudios de las Mujeres), celebrado en la Universidad de León, del 28 al 30.

. (2008): El deseo de un hijo en la literatura psicoanalítica. Tesis Doctoral. Departamento de Filosofía IV. Teoría del conocimiento e Historia del pensamiento. Madrid: Universidad Complutense.

- Evans, D. (1997): Diccionario introductoria de psicoanálisis lacaniano. Barcelona: Paidós. - Foucault, M. (1975): Vigilar y castigar. Nacimiento de la prisión. Buenos Aires: Siglo XXI Editores.

- Freud, S. (1905): Tres ensayos de teoría sexual. (1ª Edición, 1978; $9^{a}$ reimpresión, 1996). Obras Completas. Buenos Aires: Amorrortu. Tomo VII, pp. 109-224. . (1908): Sobre las teorías sexuales infantiles. (2 Edición, 1986; 4ª reimpresión, 1996). Obras Completas. Buenos Aires: Amorrortu. Tomo IX, pp. 183-201.

. (1910): Un recuerdo infantil de Leonardo da Vinci. (2 $2^{\mathrm{a}}$ Edición, 1986; $5^{\mathrm{a}}$ reimpresión, 1997). Obras Completas. Buenos Aires: Amorrortu. Tomo XI, pp. 53-127. 
(1913): Tótem y Tabú. Algunas concordancias en la vida anímica de los salvajes

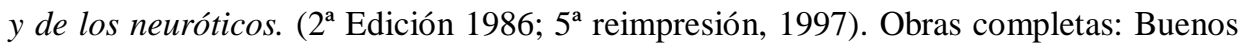
Aires: Amorrortu. Tomo XIII, pp. 1-164.

(1914): Introducción del narcisismo. (2 $2^{\mathrm{a}}$ Edición 1984; $7^{\mathrm{a}}$ reimpresión, 1996). Obras completas: Buenos Aires: Amorrortu Tomo XIV, pp. 65-98.

(1917-18): El tabú de la virginidad (Contribuciones a la psicología del amor III). (1 ${ }^{\text {a }}$ Edición, 1979, $5^{\text {a }}$ reimpresión, 1997). Obras Completas. Buenos Aires: Amorrortu. Tomo XI, pp. 185-204.

. (1920): Sobre la psicogénesis de un caso de homosexualidad femenina. ( $2^{\mathrm{a}}$ Edición, 1984, $7^{\mathrm{a}}$ reimpresión, 1997). Obras Completas. Buenos Aires: Amorrortu. Tomo XVIII, pp. 137-164.

(1923): El yo y el ello. (2 ${ }^{\mathrm{a}}$ Edición, 1984, $7^{\mathrm{a}}$ reimpresión, 1997).Obras Completas. Buenos Aires: Amorrortu. Tomo XIX, pp. 1-66.

(1927): El fetichismo. (2 $2^{\mathrm{a}}$ Edición, 1986; 5 ${ }^{\mathrm{a}}$ reimpresión, 1996). Obras Completas. Buenos Aires: Amorrortu. Tomo XXI, pp. 141-153.

(1933): “31 a Conferencia: La descomposición de la personalidad psíquica”. En

S. Freud: Nuevas Conferencias de introducción al psicoanálisis. (2 ${ }^{\mathrm{a}}$ Edición, 1986, 4ª Reimpresión, 1996). Obras Completas. Buenos Aires: Amorrortu. Tomo XXII, pp. 53-74.

. (1933a): "32 a Conferencia: Angustia y vida pulsional”. En S. Freud: Nuevas

Conferencias de introducción al psicoanálisis. Obras Completas. Buenos Aires:

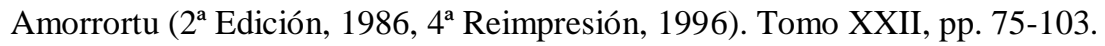
(1935): Epistolario: 1873-1939. Barcelona: Plaza y Janes, 1968. (Citado por de Mijolla, A. (2007: 626): Diccionario Internacional de Psicoanálisis. Tomo I. Madrid: Akal). (1938): Esquema del psicoanálisis. (2ª Edición, 1986; 4ª reimpresión, 1996).

Obras Completas. Buenos Aires: Amorrortu. Tomo XXIII. pp. 133-209. . (1940): La escisión del yo en el proceso defensivo. (2 ${ }^{\mathrm{a}}$ Edición, 1986; $4^{\mathrm{a}}$ reimpresión, 1996). Obras Completas. Buenos Aires: Amorrortu. Tomo XXIII, pp. 271-278.

- Glocer Fiorini, L. (2007): "Reflexiones sobre la homoparentalidad". En Rotenberg, E. y Agrest Wainer, B. (com.) Homoparentalidades. Nuevas familias. Buenos Aires: Lugar Editorial, pp. 47-56.

- Gutiérrez Terrazas, J. (2002): Cómo leer a Freud. Madrid: Síntesis.

- Hurstel, F. (1997): "De los padres <<ausentes $>>$ a los $<<$ nuevos padres $>>$. Contribución a la historia de una trasmisión genealógica colectiva”. En S. Tubert. (ed.): 
Figuras del padre. Madrid: Ediciones Cátedra. Universitat de València e Instituto de la mujer. Serie Feminismos, pp. 295-309.

- Iriarte, A. (1996): "Ser madre en la cuna de la democracia o el valor de la paternidad". En Tubert, S. (ed.): Figuras de la madre. Madrid: Ediciones Cátedra, Universitat de València e Instituto de la mujer. Serie Feminismos, pp. 73-93.

- Knibiehler, I. (1997): "Padres, patriarcado, paternidad”. En S. Tubert. (ed.): Figuras del padre. Madrid: Ediciones Cátedra. Universitat de València e Instituto de la mujer. Serie Feminismos, pp. 117-135.

- Lacan, J. (1938): La familia. (1 ${ }^{a}$ Edición, 1978). Buenos Aires: Editorial Argonatura. (1954): "Respuesta al comentario de Jean Hyppolite sobre la <<Verneinung >> de

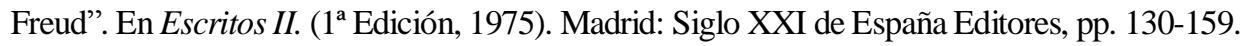
. (1956-57): El seminario de Jacques Lacan. Libro 4. La relación de objeto. 1956-1957. (1ª Edición. $1^{a}$ reimpresión, 1998). Barcelona: Paidós.

. (1957-58): El seminario de Jacques Lacan. Libro 5. Las formaciones del inconsciente. 1957-1958. (1 $1^{\text {a }}$ Edición, 1999). Barcelona: Paidós.

. (1959-60): El seminario de Jacques Lacan. Libro 7. La ética del psicoanálisis. (1ªdición, 1999). Barcelona: Paidós.

. (1964): "Del <<Trieb $>>$ de Freud y del deseo del psicoanalista". En Escritos I. (2 ${ }^{\mathrm{a}}$ Edición, 1972) Madrid: Siglo XXI de España Editores, pp. 387-390.

-Laplanche, J. (1980): Castración. Simbolizaciones. Problemáticas II. Buenos Aires: Amorrortu.

. (1987): Nuevos fundamentos para el psicoanálisis. La seducción originaria. ( $1^{\mathrm{a}}$ Edición. $1^{a}$ reimpresión: 2001). Buenos Aires: Amorrortu.

. (1992): La prioridad del otro en psicoanálisis. (1 $1^{\text {a }}$ Edición, 1996). Buenos Aires:

Amorrortu.

. (1993): El extravío biologizante de la sexualidad en Freud. (1 $1^{\text {a }}$ Edición: 1998).

Buenos Aires: Amorrortu.

- Laurent, E. (1987). “La psicosis en el niño según la enseñanza de J. Lacan”. En Descartes, 2/3. Buenos Aires, p. 16.

- Louraux, N. (1996). "La madre, la tierra". En S. Tubert: Figuras de la madre. Madrid: Ediciones Cátedra, Universitat de València e Instituto de la mujer. Serie Feminismos, pp. 53-69. 
- Maffía, D. (2007): "Familia y adopción: Reflexiones acerca de la homoparentalidad". En E. Rotenberg y B. Agrest Wainer (comp.): Homoparentalidades. Nuevas familias. Buenos Aires: Lugar Editorial, pp.56-62.

- Montejo Alonso, F. J. (2009): El psicoanálisis 1919-1933: Consolidación, expansión e institucionalización. Vol 1. Tesis Doctoral. Departamento de Filosofía IV. Facultad de Filosofía. Universidad Complutense de Madrid.

. (2009a): El psicoanálisis 1919-1933: Consolidación, expansión e institucionalización. Vol. 2. Tesis Doctoral. Departamento de Filosofía IV. Facultad de Filosofía. Universidad Complutense de Madrid.

- Naranjo, J. A. (2006): "La familia hace síntoma". En Razón del psicoanálisis. Barcelona: Escuela Lacaniana de Psicoanálisis. RBA, pp. 25- 37.

- Narotzky, S. (1997): "El marido, el hermano y la mujer de la madre: algunas figuras del padre". En S. Tubert (ed.): Figuras del padre. Madrid: Ediciones Cátedra. Universitat de València e Instituto de la mujer. Serie Feminismos, pp. 189-216.

- Roudinesco, E. (2004): La familia en desorden. Barcelona: Editorial Anagrama.

- Tubert, S. (1991): Mujeres sin sombra. Maternidad y tecnología. Madrid: Siglo XXI de España Editores, S.A.

. (ed.) (1996): Figuras de la madre. Madrid: Ediciones Cátedra, Universitat de València e Instituto de la mujer. Serie Feminismos.

. (1996a): "Introducción”. En S. Tubert (ed.): Figuras de la madre. Madrid: Ediciones

Cátedra, Universitat de València e Instituto de la mujer. Serie Feminismos, pp. 7-37. . (ed.) (1997): Figuras del padre. Madrid: Ediciones Cátedra. Universitat de València e Instituto de la mujer. Serie Feminismos. . (1997a.): "El nombre del padre". En S. Tubert (ed.): Figuras del padre. Madrid:

Ediciones Cátedra. Universitat de València e Instituto de la mujer. Serie Feminismos, pp. 31-61. 